\title{
AC 2007-2095: USING OUTCOMES-BASED ASSESSMENT AND CONTINUOUS QUALITY IMPROVEMENT PRACTICES FROM ABET PROGRAM ACCREDITATION IN INSTITUTIONAL ACCREDITATION
}

\section{Susan Scachitti, Purdue University-Calumet}

Susan is Associate Professor of Industrial Engineering Technology at Purdue University Calumet. She holds degrees in Industrial Engineering Technology from the University of Dayton and a MBA in Management from North Central College. She teaches and consults in TQM, six sigma, lean and continuous improvement. Sue is past chair of the IE Division of ASEE and formerly served as division chair, program chair, newsletter editor, and treasurer. She has served as a TAC/ABET commissioner or alternate since 2003 and program accreditation evaluator since 2001.

\section{Gregory Neff, Purdue University-Calumet}

Greg is Professor of Mechanical Engineering Technology at Purdue University Calumet. He has graduate degrees in mechanical engineering, physics, and mathematics. He is a Registered Professional Engineer, a Certified Manufacturing Engineer, and a Certified Manufacturing Technologist. He served as a TAC/ABET MET program accreditation visitor from 1996 to 2003, as secretary, program chair, chair and past chair of the MET Department Heads Committee of ASME. He served on the Technology Accreditation Commission of ABET 2003 to 2006. He won the ASEE Meryl K. Miller Award in 1994.

\section{Christine Corum, Purdue University}

Christine is Associate Professor of Mechanical Engineering Technology at Purdue University West Lafayette. She is MET Coordinator of Strategic Planning and Accreditation. She is a member of the Committee on Technology Accreditation of ASME and serves on the Technology Accreditation Commission of ABET. Chris received a B.S. in Metallurgical Engineering from the University of Missouri-Rolla and an M.S. in Industrial Engineering from Purdue University. She has 10 years of industrial experience.

\section{James Higley, Purdue University, Calumet}

Jim holds the rank of Professor of Mechanical Engineering Technology at Purdue University Calumet. He is a registered P.E. in Indiana. He is responsible for coordinating the Mechanical Engineering Technology program, as well as teaching courses in parametric modeling; integrated design, analysis \& manufacturing; manufacturing processes; and thermodynamics. He holds Bachelor and Masters degrees in mechanical engineering from Purdue University.

\section{Mohammad Zahraee, Purdue University-Calumet}

Mohammad is Professor and Head of the Department of Manufacturing Engineering Technologies and Supervision at Purdue University Calumet. He received his Ph.D. in Theoretical and Applied Mechanics from the University of Illinois. He is a registered P.E. in Indiana. He is the recipient of the ASME Distinguished Service Award and the Ben Sparks Metal. Mohammad has been a TAC (Technology Accreditation Commission) MET evaluator for ABET since 1992 and is currently chair of operations of TAC serving on the commission since 1997.

\section{Heather Cooper, Purdue University}




\title{
Using Outcomes Based Assessment and Continuous Quality Improvement Practices from ABET Program Accreditation in Institutional Accreditation
}

\begin{abstract}
Now that programs have experience with Accreditation Board for Engineering and Technology (ABET) Technology Accreditation Commission (TAC) and Engineering Accreditation Commission (EAC) general reviews, this paper will look at how faculty are using the outcomes based assessment and continuous quality improvement practices needed for ABET program accreditation criteria TC2K and EC2000 in meeting institutional accreditation requirements used to accredit colleges and universities by the Higher Learning Commission (HCL) of the North Central Association of Colleges and Schools (NCA). The paper will also look at the other five regional associations, each named after the region in which it operates (Middle States, New England, Northwest, Southern, Western) to show similarities in the assessment approach each is currently using compared to NCA and ABET.
\end{abstract}

\section{Introduction}

"Is one educational accreditation process just like the other?" This is the question that faculty at various Purdue campuses have been asking starting with Corum in $2000^{1}$. Over the past 30 years industries that partner with educational institutions have been re-engineering their understanding and utilization of quality methods and terminology, but it has only been in the past decade that the educational accreditation bodies have been infusing these new quality methods and terms into educational institutions. In the case of regional college and university accreditation commissions, there is now significant agreement among the bodies. As the Northwest Commission on Colleges and Universities states ${ }^{2}$ :

"While the procedures of the regional accrediting bodies differ somewhat in detail to allow for regional variations, their rules of eligibility, basic policies, and levels of expectation are similar. Given these variations in detail, regional accreditation of higher education institutions is intended to:

1. foster excellence in higher education through the development of criteria and guidelines for assessing educational effectiveness;

2. encourage institutional improvement of educational endeavors through continuous self-study and evaluation;

3. ensure the educational community, the general public, and other agencies or organizations that an institution has clearly defined and appropriate educational objectives, has established conditions under which their achievement can reasonably be expected, appears in fact to be substantially accomplishing them, and is so organized, staffed, and supported that it can be expected to continue to do so; and

4. provide counsel and assistance to established and developing institutions."

The regional associations are independent of one another, but they cooperate extensively and acknowledge one another's accreditation. For example, the Council of Regional Accrediting Commissions (CRAC), an organization of the six regional accreditation commissions in the United States developed three documents or guides to assist institutions in the US in the area of 
student learning with the help of a grant from The Pew Charitable Trusts. The documents provide a framework within which institutions, regardless of regional affiliations, might give a central focus to student learning as a demonstration of institutional quality ${ }^{3}$.

To illustrate the philosophies that guide the direction that institutional accreditation criterion will move and point out regional similarities and differences see, Appendix 1 which lists the accreditation commissions' mission statements.

\section{Academic Quality Improvement Program of the Higher Learning Commission of the North Central Association of Colleges and Schools}

The Academic Quality Improvement Program (AQIP), the name for one accreditation approach by the North Central Association (NCA) of colleges and schools, was launched in July 1999 with the help of a grant from the Pew Charitable Trusts. AQIP promotes the principles and benefits of continuous improvement and requires their adoption into the culture of colleges and universities joining the program. AQIP is an alternative process through which an already-accredited institution can maintain its accreditation from the Higher Learning Commission. An existing NCA accreditation would come from the standard NCA accreditation model known as PEAQ (Program to Evaluate and Advance Quality).

The AQIP model is based on the Malcolm Baldrige National Quality Award Program and incorporates a continuous review and feedback process. Additionally, it provides assurance of institutional quality to NCA and other stakeholders. The regular process (PEAQ) provides a "snapshot" at ten year intervals. Purdue University Calumet's parent campus, Purdue University West Lafayette, for example uses the NCA PEAQ. In fact, only 174 predominantly small and middle sized colleges and universities of the 1307 NCA accredited institutions use AQIP. Both AQIP and PEAQ accreditation models depend on the same NCA accreditation criteria. By comparison, about 3500 institutions are accredited by the six regional accrediting agencies nationally.

Every college or university participating in AQIP continuously works on at least three action projects. If an institution completes a project, AQIP assumes it will begin a new one, using the knowledge and skills gained from its earlier projects to select, shape, and scope the replacements. During a seven year period institutions create and maintain a Systems Portfolio, which is periodically appraised. Institutions also engage in all other AQIP processes, including Strategy Forums, Annual Updates on action projects, and undergo a visit to review U.S. Department of Education compliance issues.

\section{The Purdue University Calumet Experience}

At Purdue University Calumet, several accreditation bodies are periodically invited to review programs at various degree levels, but details of the evaluation process vary. This is becoming increasing clear as faculty at Purdue University Calumet (PUC) work on preparing for NCA accreditation using the AQIP model. NCA accreditation is accreditation of the entire University. Various programs within the University have subsequently attained individual program level accreditations as well. At PUC the Engineering and Engineering Technology programs are 
accredited by ABET. The PUC faculty that have gone through the ABET accreditation process have found that they are well prepared for the AQIP process. This is because the program accreditation processes that they have experienced are approaches that are considered Continuous Quality Improvement approaches. The basis of this approach is developing a strategic vision to be accomplished. This vision is then supported and carried out by goals and objectives identified at various levels within the organization. The outcomes of the organization's actions are then assessed to evaluate attainment of these goals and objectives that in turn were created to support the strategic vision.

As part of the AQIP process, Purdue University Calumet created a task force in the spring, 2006 semester to address various issues related to this accreditation process. The Academic Program Review Committee (APRC) was charged with reviewing the status of currently accredited PUC undergraduate programs and developing a procedure for evaluation of those programs without external accreditation.

After meeting and examining existing undergraduate programs, the APRC found the following accredited programs at PUC:

- Several engineering programs accredited by the Engineering Accreditation Commission of Accreditation Board for Engineering and Technology (EAC/ABET)

- Several technology programs accredited by the Technology Accreditation Commission of Accreditation Board for Engineering and Technology (TAC/ABET)

- Several Management programs accredited by International Assembly for Collegiate Business Education (IACBE)

- Several Nursing programs accredited by The National League for Nursing Accrediting Commission (NLN Accrediting Commission).

- Several Education programs accredited by the National Council for Accreditation of Teacher Education (NCATE).

In addition, the APRC noted the following programs without external accreditation:

- Biological Sciences

- Chemistry/Physics

- Mathematics, Computer Science, and Statistics

- Behavior Sciences

- Communication and Creative Arts

- English and Philosophy

- Foreign Languages and Literatures

- Computer Information Technology

As the committee reviewed the individually accredited programs, many similarities became evident. One would expect similarities between engineering and technology programs, but the committee noted that all program accreditation requirements are quite similar. All accredited program criteria are now outcomes based. Some programs such as engineering and technology have more freedom to design outcomes while others such as education and nursing are more constrained to a fixed set of outcomes. All committee members easily understood requirements from other programs. Casual discussions also noted similar experiences in overcoming initial faculty reluctance and developing continuous improvement and assessment processes. In 
addition, benefits such as clearly defined constituencies, easily compared numeric values for goals and outcomes, and ease of evaluating new procedures etc. were also noted.

As the Academic Program Review Committee reviewed the non-accredited programs, many differences arose. Some programs faculty have opted for external reviews using reviewers chosen from professional societies, while other programs have done very little in the way of outcomes development. At this point, the committee asked all PUC programs to develop outcomes and assessment plans based on material from the University of Michigan, Flint ${ }^{4}$. After some months, most programs succeeded in creating outcomes-based assessment plans. As the APRC reviewed the plans in the fall, 2006 semester, the most commonly missed item noted was a feedback loop to evaluate assessment data and act upon the information.

Currently, Purdue University Calumet's APRC is developing a consistent procedure to have nonaccredited programs evaluated by external, invited professionals in a manner similar to accredited programs. The APRC will then review the accreditation and evaluation reports in the semester after the reports are finalized. This will give all the programs at Purdue University Calumet uniform, external comparison which will help maintain and improve program quality.

\section{Assessment Approaches of Regional Associations}

As described in the abstract, there are six regional accrediting agencies within the United States:

- Higher Learning Commission (HCL) of the North Central Association of Colleges and Schools (NCA)

- Middle States Commission on Higher Education

- New England Association of Schools and Colleges

- Northwest Commission on Colleges and Universities

- Commission on Colleges of the Southern Association of Colleges and Schools

- The Western Association of Schools and Colleges

Appendix 1 includes a list of states assigned to each accrediting agency and the stated mission of each. A comparison of the missions gives support to the common purpose of regional accreditation agencies stated by the Northwest Commission on Colleges and Universities in the introduction to this paper. "Quality improvement, quality assurance, continuous improvement" or similar terminology is used in each.

A review and comparison of key accreditation criterion from each agency shows that the NCA key criterion has developed into a focus of five areas whereas the remaining agencies have maintained a more detailed list of criterion. A comparison table of key criteria is included in Appendix 2.

The NCA key criteria are as follows ${ }^{5}$ :

- Criterion One: Mission and Integrity. The organization operates with integrity to ensure the fulfillment of its mission through structures and processes that involve the board, administration, faculty, staff, and students. 
- Criterion Two: Preparing for the Future. The organization's allocation of resources and its processes for evaluation and planning demonstrate its capacity to fulfill its mission, improve the quality of its education, and respond to future challenges and opportunities.

- Criterion Three: Student Learning and Effective Teaching. The organization provides evidence of student learning and teaching effectiveness that demonstrates it is fulfilling its educational mission.

- Criterion Four: Acquisition, Discovery, and Application of Knowledge. The organization promotes a life of learning for its faculty, administration, staff, and students by fostering and supporting inquiry, creativity, practice, and social responsibility in ways consistent with its mission.

- Criterion Five: Engagement and Service. As called for by its mission, the organization identifies its constituencies and serves them in ways both value.

The comparison table in Appendix 2 shows that there are strong connections between all six agencies in the first three areas of mission, the future, and student learning. It is difficult, though, to find correlations for the last two NCA criteria concerning knowledge and engagement. They may be tied into a given institution's mission and vision, however the remaining five agencies do not draw specific attention to the areas of knowledge or engagement within their key criteria. The comparison table also shows the ABET/TAC general criteria and the authors present an organization of the ABET/TAC criteria compared to the regional accrediting agency criteria. ABET/TAC general criteria are criteria applicable to every engineering technology program. The ABET/TAC criteria was included as an example of outcomes based assessment criteria. Not surprisingly, since ABET/TAC criteria are program focused and not institution focused, there is a strong relationship to student learning. Although there is not a strong match between ABET/TAC criteria and the institutional accrediting criteria from regional accreditation agencies, the expectation of assessment, evaluation and improvement in a continuous cycle exists in all of them.

\section{Conclusion}

Departments with program specific accreditations that are using a continuous quality improvement (CQI) process such as TC2K and EC2000 are much better prepared than those with unaccredited programs to help their institutions prepare for institutional accreditation visits including alternate CQI processes like AQIP since the regional higher education accreditation organizations are inexorably moving toward CQI processes as they move away from "bean counting" to student learning as a demonstration of institutional quality ${ }^{6}$. Although there is not a strong match between current criteria of the regional agencies and the example of ABET/TAC program criteria, the expectation of assessment, evaluation and improvement in a continuous cycle pervades through them all. Program faculty, experienced and successful at outcomes based program assessment, are now also prepared to demonstrate to colleagues teaching unaccredited programs, the value in CQI that industry has known for years but which is just now entering higher education. 


\section{Bibliography}

1. Corum, Christine L, "Evolution of Assessment within a Mechanical Engineering Technology Department," ASEE Annual Conference and Exposition Proceedings, St. Louis, Mo., June 18-21, 2000, Session 2548, referenced from the Internet 1/17/2007 at http://www.asee.org/acPapers/20225.pdf.

2. Northwest Commission on Colleges and Universities, Accreditation Handbook, 2003 Edition, Redmond, WA 98052-3981, referenced from the Internet 1/17/2007 at http://www.nwccu.org/Pubs Forms and Updates/Publications/Accreditation Handbook 2003 Edition Updated September 1 2005.pdf

3. Council of Regional Accrediting Commissions, Regional Accreditation and Student Learning: A Guide for Institutions and Evaluators, referenced from the Internet 1/17/2007 at http://www.sacscoc.org/pdf/handbooks/GuideForInstitutions.pdf, Regional Accreditation and Student Learning: Improving Institutional Practice, referenced from the Internet 1/17/2007 at http://www.sacscoc.org/pdf/handbooks/ImprovingPractice.pdf, and Regional Accreditation and Student Learning: Preparing Teams for Effective Deliberation, referenced from the Internet 1/17/2007 at http://www.sacscoc.org/pdf/handbooks/PreparingTeams\%28blue\%29.pdf.

4. University of Michigan, Flint, The University of Michigan-Flint Assessment Handbook, Committee on Assessment, Accreditation and Strategic Planning (CAASP), Use by Purdue University Calumet approved by Provost of University of Michigan-Flint on July 5, 2006

5. The Higher Learning Commission. (2003). Institutional accreditation, an overview. Chicago, IL: Author

6. ABET Technology Accreditation Commission. (2006). Criteria for accrediting engineering technology programs 2006-2007 accreditation cycle. Baltimore, MD: Author. 


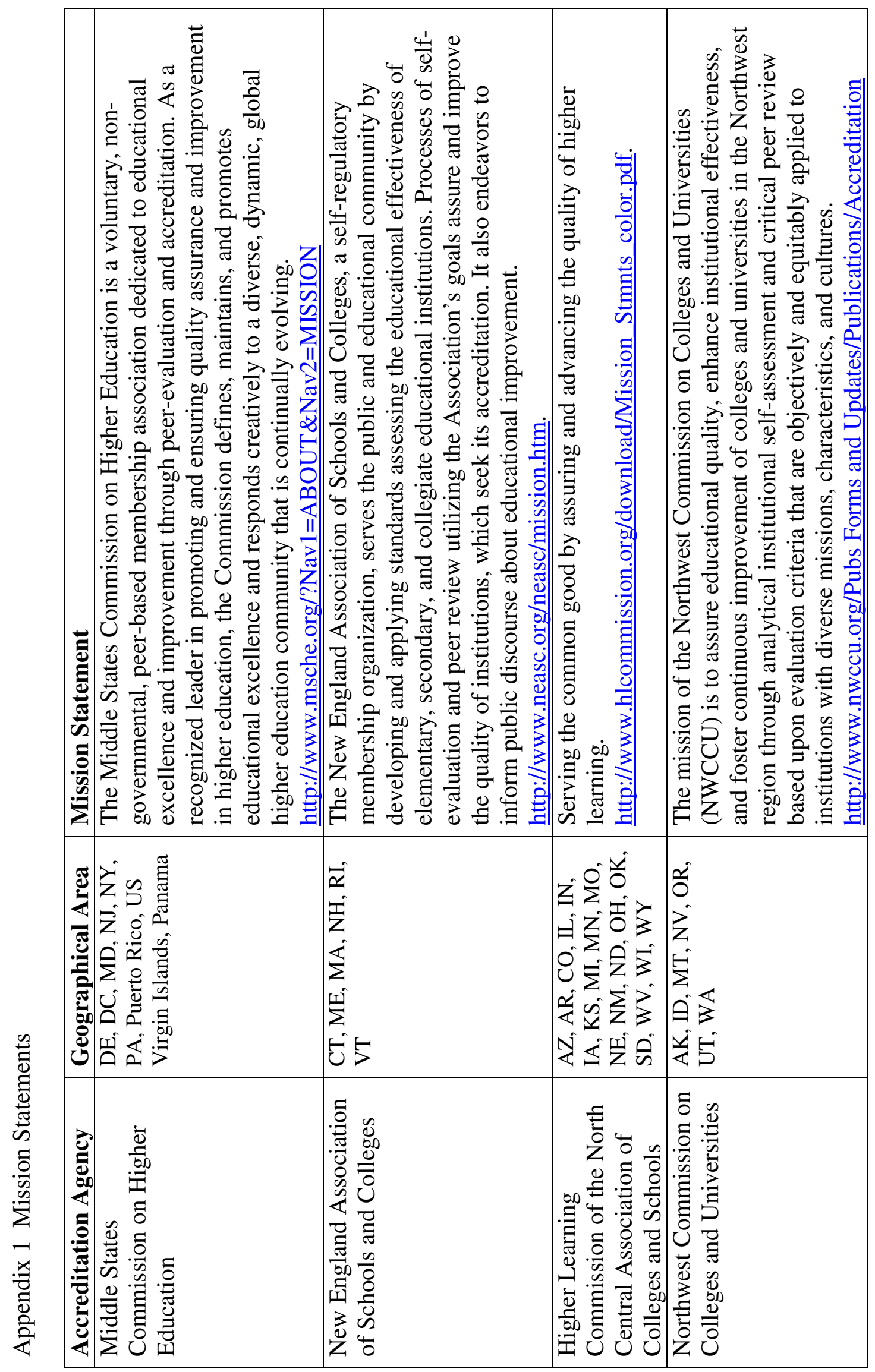




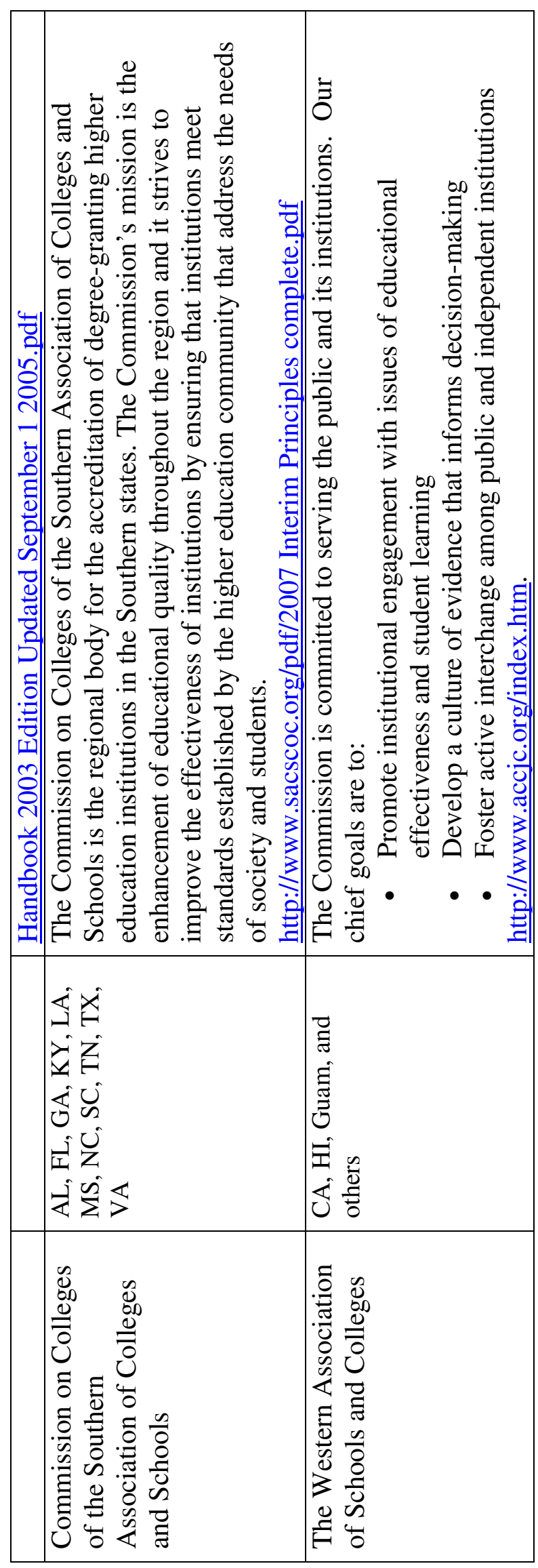

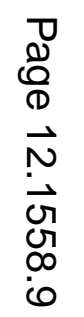




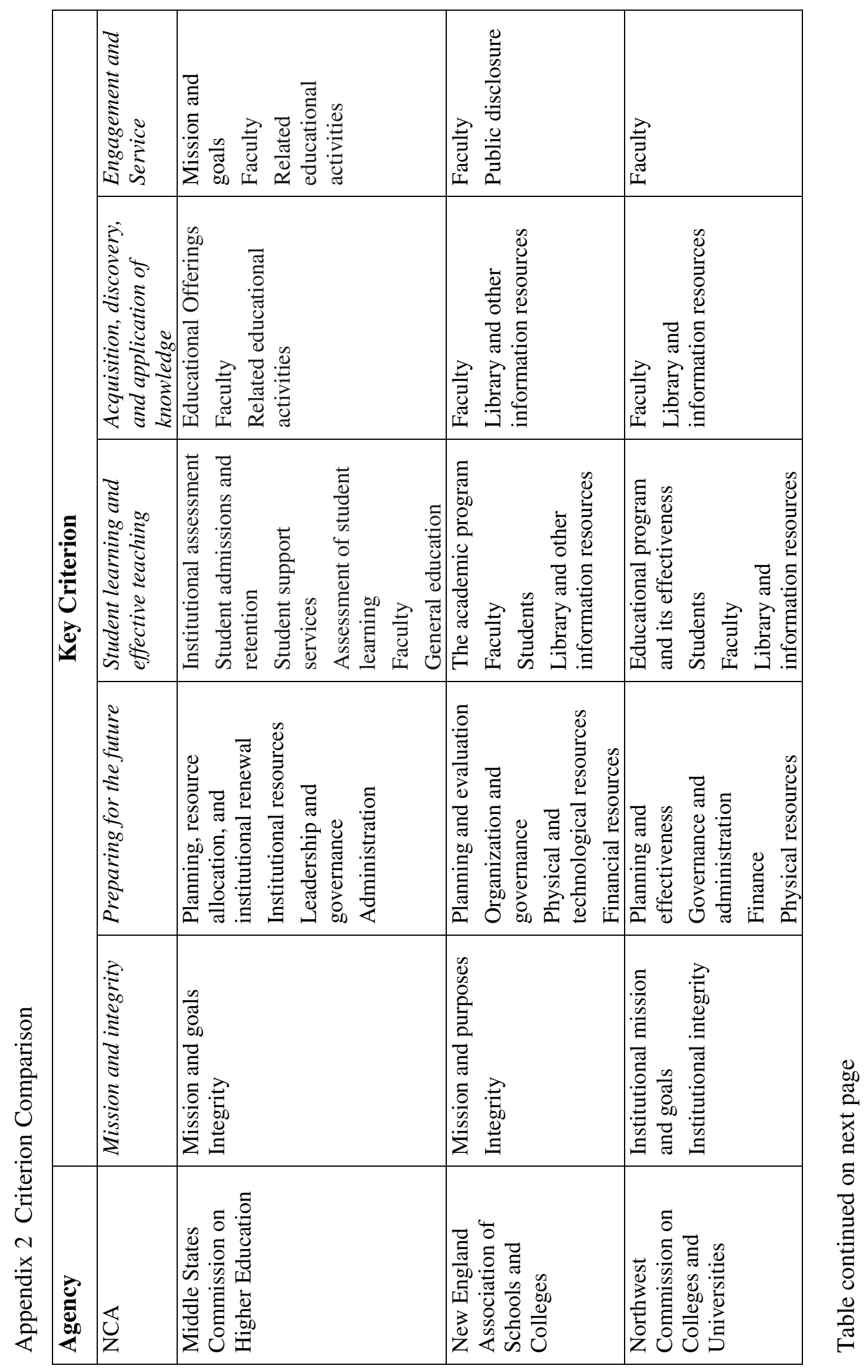




\begin{tabular}{|c|c|c|c|c|}
\hline \multirow{5}{*}{ 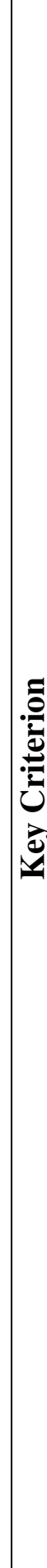 } & 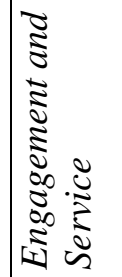 & 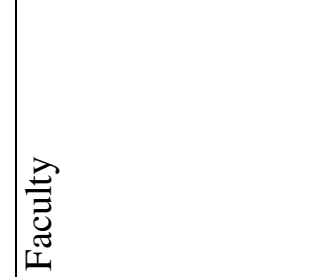 & & 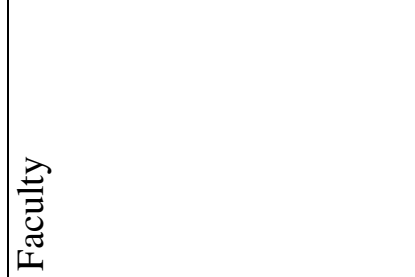 \\
\hline & 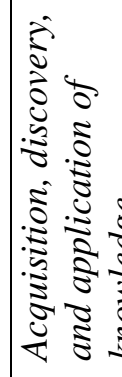 & 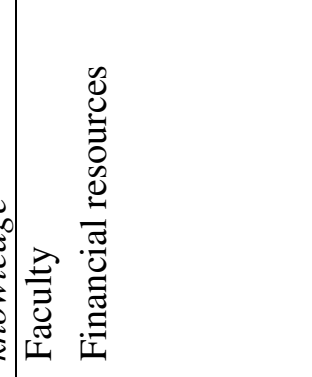 & 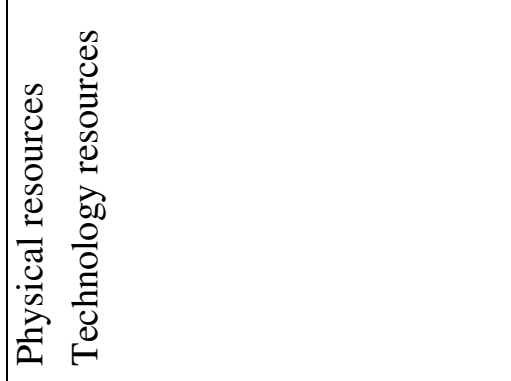 & 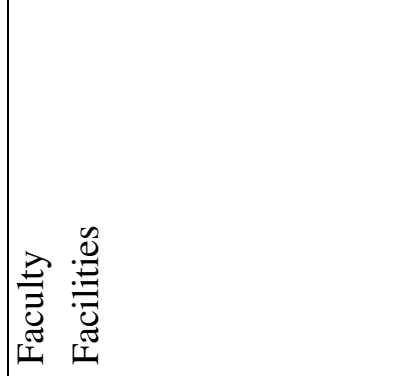 \\
\hline & 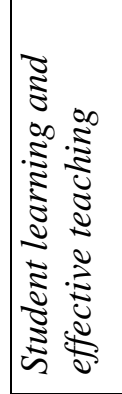 & 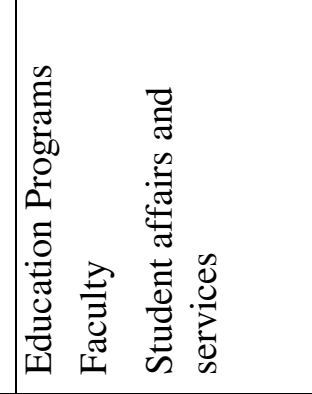 & 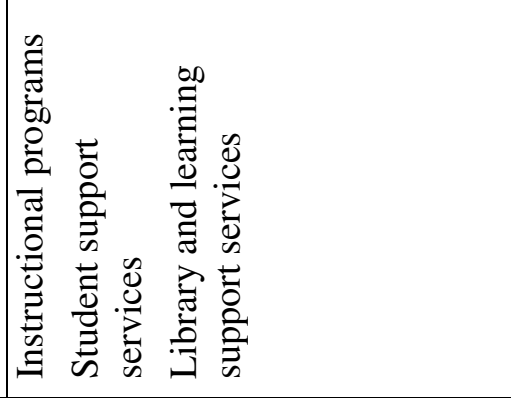 & 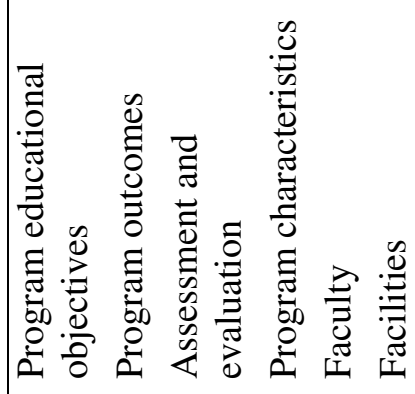 \\
\hline & 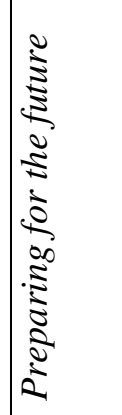 & 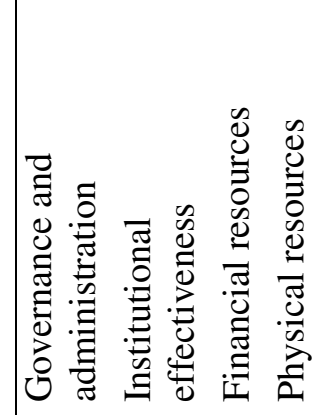 & 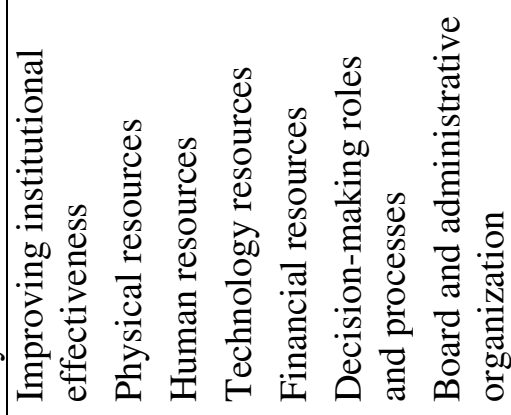 & 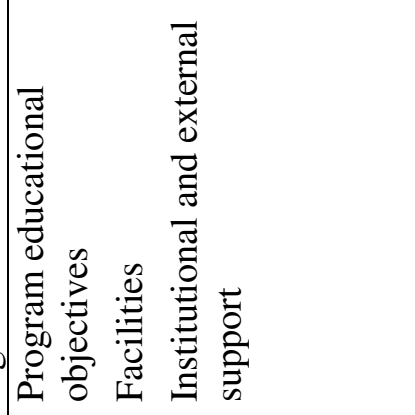 \\
\hline & 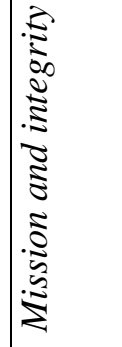 & 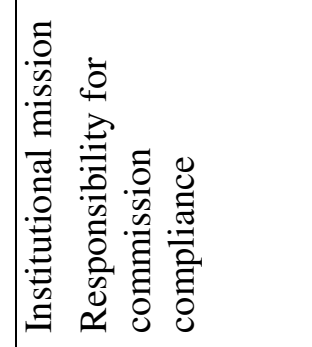 & 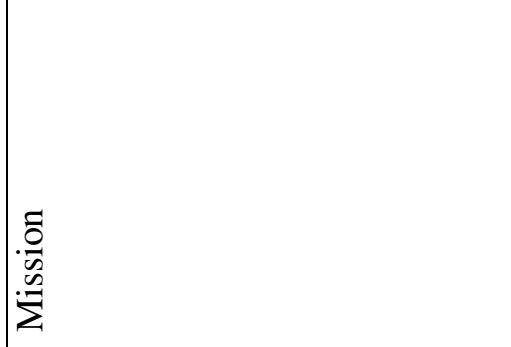 & 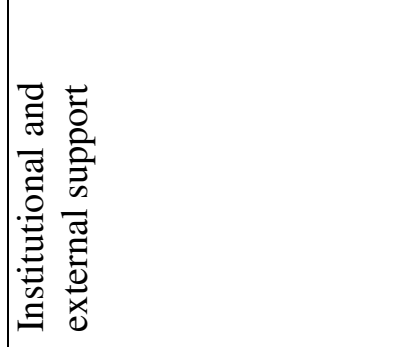 \\
\hline 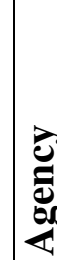 & 远 & 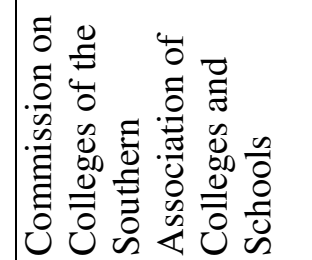 & 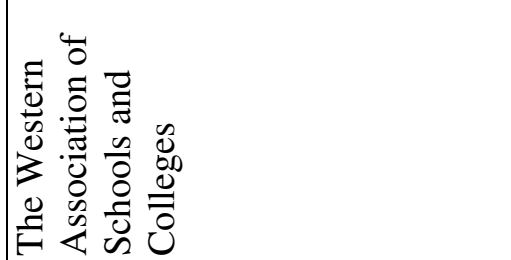 & 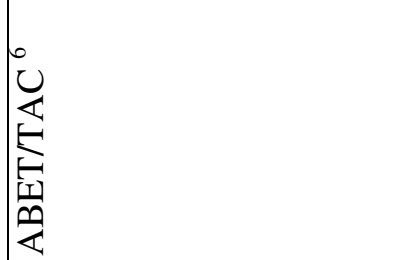 \\
\hline
\end{tabular}

